\title{
QUALIDADE DO PROCESSO DE SEMEADURA DA CULTURA DO MILHO DE SEGUNDA SAFRA
}

\author{
Sálvio Napoleão Soares Arcoverde ${ }^{1}$, Cristiano Márcio Alves de Souza ${ }^{2}$, Jorge Wilson Cortez ${ }^{3}$, Renato Anastacio \\ Guazina ${ }^{4}$, Paulo Alexandre Graciano Maciak ${ }^{5}$
}

\begin{abstract}
RESUMO
A semeadura do milho está sujeita a fatores que podem interferir na qualidade da operação. O uso de métodos estatísticos de controle de qualidade em processos agrícolas tem-se mostrado eficiente para detecção de variabilidade no decorrer da operação. Objetivou-se avaliar a qualidade e capabilidade da semeadura do milho de segunda safra por semeadoraadubadora pneumática. A coleta de dados ocorreu no município de Dourados (MS) em área de aproximadamente 30 ha, utilizando-se malha amostral composta de 60 pontos distribuídos na área com uma amostra a cada 0,5 ha. Determinaram-se a quantidade de plântulas emergidas e a distância entre plantas em dois metros consecutivos, a fim de calcular o estande de plantas por metro e a porcentagem de espaçamentos normais, falhos e duplos. Realizouse, inicialmente, análise descritiva e controle estatístico do processo (CEP) para caracterizar os dados e averiguar a estabilidade da semeadura do milho, que serviram como pressupostos para realizar análise de capabilidade do processo. O estande e a distribuição longitudinal de plantas em espaçamentos normais foram satisfatórios, embora abaixo da capacidade da semeadora-adubadora pneumática. O CEP permitiu avaliar a qualidade das variáveis durante o processo de semeadura, demostrando instabilidade para porcentagem de espaçamentos normais e controle dos demais indicadores de qualidade de semeadura. A análise de capabilidade indicou que a semeadora pneumática não atingiu as metas estabelecidas para estande de plantas $\left(5\right.$ plantas $\left.\mathrm{m}^{-1}\right)$ e espaçamentos falhos e duplos $(10 \%)$, sugerindo necessidade de monitoramento da operação.
\end{abstract}

Palavras-chave: controle estatístico do processo, distribuição longitudinal de sementes, plantio direto

\section{ABSTRACT \\ QUALITY PROCESS OF SEEDING OF CULTURE OF THE SECOND CORN CROP}

Seeding corn is subject to factors that may affect the quality of the operation. The use of statistical quality control methods in agricultural processes has shown to be efficient for detection of variability during the operation. The aim was evaluate the quality and capability of seeding of corn seeding second crop by pneumatic fertilizer-seeder spreader. The data sampling occurred on a commercial farm of 30 ha, located in Dourados (MS) city, using the sampling grid composed of 60 points was distributed in the area by means of a computerized system with one samples every 0.5 ha. The amount of seedlings emerged and the distance between plants in two meters, in order to calculate the stand of plants per meter and percentage of normal, double and fails spacing. It held initially descriptive analysis and statistical process control (SPC) to characterize the data and determine the stability of the corn seeding, serving as assumptions to perform capability analysis process. The stand and the longitudinal distribution of plants in normal spacings were satisfactory, although below the capacity of the air seeder. The SPC allowed to evaluate the quality of the variables during the seeding process, showing instability percentage of normal spacing and control of other seeding quality indicators. The capability analysis indicated that the pneumatic seeder did not reach the targets set for plant stand (5 plants $\mathrm{m}^{-1}$ ) and fails and double spacing $(10 \%)$, suggesting the need for monitoring the operation.

Keywords: process statistical control, seed longitudinal distribution, no-tillage

\section{Recebido para publicação em 20/06/2016. Aprovado em 10/10/2016.}

1 - Engenheiro Agrícola e Ambiental, Doutorando em Agronomia, UFGD/Dourados-MS, salvionapoleao@gmail.com

2 - Engenheiro Agrícola, Professor Associado da UFGD/Dourados-MS, csouza@ufgd.com.br

3 - Engenheiro Agrônomo, Professor Adjunto da UFGD/Dourados-MS, jorgecortez@ufgd.com.br

4 - Engenheiro Agrônomo, Doutorando em Agronomia, UFGD/Dourados-MS, renatoguazina@hotmail.com

5 - Graduando do curso de Engenharia Agrícola, UFGD/Dourados-MS, maciak_pagm@hotmail.com 


\section{INTRODUÇÃO}

A semeadura do milho de segunda safra tem aumentado no Brasil e de modo significativo no Mato Grosso do Sul, onde os rendimentos advindos dessa modalidade de exploração são iguais ou superiores aos obtidos nas semeaduras em época normal.

No entanto, a elevada variabilidade espacial e temporal de aspectos relacionados ao desenvolvimentoda culturainfluenciama população e a distribuição de plantas e, consequentemente, a produtividade (SILVA et al., 2012; VIAN et al., 2016). Esses componentes de produtividade são sensíveis a eventos meteorológicos durante a semeadura do milho (elevada umidade do solo associada às baixas temperaturas, desfavoráveis à germinação e ao desenvolvimento da plântula), e dependem da distribuição de sementes pela semeadora (VIAN et al., 2016).

A boa uniformidade de distribuição longitudinal de sementes, que pode ser avaliada pela porcentagem e variabilidade de espaçamentos normal, falho e duplo, é essencial para um estande adequado de plantas e, consequentemente, para a melhoria da produtividade das culturas (SANTOS et al., 2011; SANGOI et al., 2012). Isso é possível por meio de regulagem e operação adequadas de semeadoras com dosadores de precisão, que depositam sementes em densidade de semeadura pré-estabelecida de acordo com a recomendação da cultura (DIAS et al., 2014).

A semeadura do milho feita por semeadoraadubadora pneumática tem como meta de no mínimo $90 \%$ de espaçamentos normais na distribuição longitudinal de sementes (TOURINO et al., 2009; MELO et al., 2013; WEIRICH NETO et al., 2015). Porém, devido à elevada variabilidade de processos agrícolas esse resultado dificilmente ocorre, visto que o processo varia em função da matéria-prima, condições edafoclimáticas, sistemas mecanizados, índices de qualidade de operações agrícolas, qualificação de operadores, entre outros (ALBIEIRO et al., 2012)

Neste contexto, tem-se aplicado o controle estatístico de processo (CEP) na agricultura com o intuito de identificar fatores críticos relacionados à eficiência e eficácia das operações agrícolas, por meio do controle efetivo de variáveis, limitandoas a padrões aceitáveis (NORONHA et al., 2011; MELO et al., 2013; VOLTARELLI et al., 2015). Com isso, pode-se verificar a estabilidade das operações agrícolas, indicando se a instabilidade ou variabilidade do processo agrícola ocorre em decorrência de causas aleatórias (intrínsecas), ou de causas especiais (extrínsecas), as quais fazem com que o processo não atenda aos limites de controle estabelecidos (VOLTARELLI et al., 2015).

Por outro lado, a capabilidade do processo, além de constituir-se uma ferramenta aplicada para análise da estabilidade e variabilidade do processo, analisa a posição de indicadores em relação aos limites estabelecidos. Pode ser empregada quando verificado os pressupostos de normalidade dos dados e controle estatístico do processo, auxiliando o gerenciamento da atividade (TOLEDO, 2008; VOLTARELLI, 2013).

Pressupõe-se que o uso de métodos estatísticos de controle do processo permitirá avaliar a qualidade da semeadura do milho de segunda safra por meio de indicadores em relação a limites estabelecidos, visando à melhoria contínua da operação mecanizada. Desse modo, o objetivo do trabalho foi avaliar a qualidade da semeadura do milho de segunda safra, analisando o estande e a distribuição longitudinal de plantas por meio da estatística clássica e métodos de controle estatístico do processo.

\section{MATERIAL E MÉTODOS}

A coleta de dados foi realizada em uma propriedade localizada no município de Dourados, MS (22 $24^{\prime}$ latitude sul; $55^{\circ} 02^{\prime}$ longitude oeste; altitude média de 434 metros). O clima é do tipo Cwa (mesotérmico úmido, verões quentes e invernos secos), segundo a classificação de Köppen. O solo da área usada no trabalho foi classificado como sendo Latossolo Vermelho distroférrico, textura argilosa (EMBRAPA, 2006). O teor de água do solo era de $0,36 \mathrm{~kg} \mathrm{~kg}^{-1}$ e a densidade de $1,14 \mathrm{Mg}$ $\mathrm{m}^{-3}$, na camada de $0,00-0,10 \mathrm{~m}$.

$\mathrm{Na}$ fazenda, cultiva-se como cultura de verão soja (Glycine max) e inverno milho (Zea mays), em um sistema de sucessão de culturas sem revolvimento do solo, no qual o sistema semeadura

\section{REVENG}


direta sobre a palha vem sendo adotado por mais de 20 anos. O trabalho foi conduzido em uma área de aproximadamente 30 hectares.

Aárea foi semeada no mês de fevereiro de 2016, utilizando-se como cultivar um híbrido simples modificado (AG-9030) com 95\% de pureza e $85 \%$ de germinação. Na semeadura foi utilizado um trator $4 \mathrm{x} 4$ New Holland, modelo NEFTM de potência de acionamento no motor de $134 \mathrm{~kW}$ $(182 \mathrm{cv})$, pneus traseiros R1 24.5-32 e dianteiros 18.4-26, e massa de $6.725 \mathrm{~kg}$. Foi utilizada a semeadora-adubadora de precisão da marca John Deere, modelo 1113, equipada com 12 unidades de semeadura com mecanismos sulcadores tipo haste para fertilizante e discos duplos defasados para sementes e com mecanismo dosador de sementes pneumático a vácuo com 30 furos. A mesma foi regulada para distribuir 5 sementes de milho por metro, na profundidade de $0,05 \mathrm{~m}$, com velocidade de $8,0 \mathrm{~km} \mathrm{~h}^{-1}$.

Para as avaliações, foi utilizada uma malha amostral composta de 60 pontos amostrais distribuídos na área com uma amostra a cada 0,5 hectares. Em cada ponto foi determinado o estande de plantas por meio da coleta de uma amostra do número de plântulas de milho emergidas em dois metros consecutivos, bem como realizada a avaliação de distribuição longitudinal ou uniformidade de espaçamentos entre plântulas do milho com auxílio de trena graduada com a precisão de $0,05 \mathrm{~m}$.

Deste modo, determinaram-se a porcentagem de espaçamentos normais, falhos e duplos de acordo com a norma de Kurachi et al. (1989), considerando-se porcentagens de espaçamentos: "duplos" (D): $\leq$ 0,5 vez o Xref, "normais" (A): $0,5<$ Xref $\leq 1,5$, e "falhos" (F): > 1,5 vez o Xref, em que Xref é o valor do espaçamento de referência calculado de acordo com a regulagem da semeadora-adubadora para a operação. Assim, os espaçamentos entre plantas $(\mathrm{X})$ foram classificados como normais $(0,138 \mathrm{~m}<\mathrm{X} \leq 0,325 \mathrm{~m})$, duplos ( $\mathrm{X}$ $\leq 0,138 \mathrm{~m})$ e falhos $(X>0,325 \mathrm{~m})$.

Primeiramente, os dados foram analisados por meio da estatística descritiva, para permitir à visualização geral do comportamento dos dados, além de verificada a normalidade dos mesmos utilizando o teste de Ryan-Joiner. Todas as variáveis foram avaliadas por meio do controle estatístico do processo (CEP), utilizando-se das cartas de controle de valores individuais, que possuem linhas centrais (média geral), bem como os limites inferior e superior de controle (LCL e UCL), respectivamente, calculados com base no desvio padrão das variáveis: para LCL, média menos três vezes o desvio padrão, e para UCL, média mais três vezes o desvio padrão (PELOIA et al., 2010; NORONHA et al., 2011; CASSIA et al., 2013; SILVA et al., 2013; VOLTARELLI et al., 2013; VOLTARELLI et al., 2015).

Ressalta-se que, para os indicadores porcentagem de espaçamento falho e duplo, a avaliação da estabilidade do processo utilizandose das cartas de controle de valores individuais, descritas anteriormente, pode resultar em LCL negativo. Neste caso, a avaliação será condicionada pelo UCL, visto que o valor mínimo para estes indicadores é zero. Ou seja, o LCL negativo nas cartas de controle é meramente ilustrativo, e sua existência é resultado do cálculo a partir dos dados do processo, portanto, não devendo ser confundido com limites especificados (agronômicos/ mecânicos). Do mesmo modo para o espaçamento normal, que obteve UCL superior $100 \%$; portanto, devendo-se considerar somente o LCL na avaliação da estabilidade do processo.

Após a verificação dos pressupostos de normalidade dos dados e controle estatístico do processo, realizou-se a análise de capabilidade do processo, que foi representada por um histograma, utilizado para verificar a normalidade dos dados e um quadro de índices de capabilidade, utilizados para calcular a quantidade de defeitos ou produtos fora das especificações que o processo poderá produzir, sem e com a remoção das causas não inerentes, quando houver (TOLEDO, 2008).

Os limites inferiores especificados e superiores especificados (LIE e LSE) e a meta a ser atingida são representados graficamente pelas linhas verticais no histograma de capabilidade. Comparando o histograma com estas linhas, podem-se verificar a quantidade de observações próximas à meta e as observações que se encontram dentro dos limites especificados (TOLEDO, 2008). Assim, para este tipo de análise foram aplicadas metas para o estande de plantas e distribuição longitudinal 
Quadro 1. LIE, LSE e meta para estande e distribuição longitudinal de plântulas de milho para uma semeadora-adubadora pneumática

\begin{tabular}{lcccc}
\hline Parâmetros & $\begin{array}{c}\text { Estande } \\
\left(\text { plantas }^{-1}\right)\end{array}$ & $\begin{array}{c}\text { Normal } \\
(\%)\end{array}$ & $\begin{array}{c}\text { Falho } \\
(\%)\end{array}$ & $\begin{array}{c}\text { Duplo } \\
(\%)\end{array}$ \\
\hline LIE & 4,0 & 90 & 0 & 0 \\
Meta & 5,0 & 95 & 10 & 10 \\
LSE & 6,0 & 100 & 20 & 20 \\
\hline
\end{tabular}

de plântulas durante o processo de semeadura. Os limites agronômicos/mecânicos estabelecidos foram baseados nas recomendações de campo ou de projeto: estande de plantas (LIE $=4$ plantas $\mathrm{m}^{-1} \mathrm{e}$ $\mathrm{LSE}=6$ plantas $\left.\mathrm{m}^{-1}\right)$, distribuição longitudinal para semeadora-adubadora pneumática de no mínimo $90 \%$ de espaçamentos normais, que foi estipulado como LIE; e os espaçamentos falhos e duplos foram considerados como LSE de 20\% (Quadro 1).

Os índices calculados pela análise de capabilidade são adimensionais podendo ser usados para comparar a capacidade de diferentes processos. Os índices, conforme Toledo (2008) são: $\mathrm{Cp}=$ índice de capabilidade potencial; $\mathrm{Cpk}=$ índice de capabilidade potencial mínimo; $\mathrm{Pp}=$ índice de capabilidade geral; Ppk = índice de capabilidade mínimo geral; $\mathrm{Cpm}=$ índice de capabilidade em relação à meta. $\mathrm{O}$ índice de capabilidade admitido para a análise do processo foi de 1,33 , sendo o mínimo admissível para predizer se um processo é capaz de produzir resultados satisfatórios.

\section{RESULTADOS E DISCUSSÃO}

Para o indicador estande de plantas por metro observou-se que a média e a mediana encontram-se próximas, e apesar de os valores do desvio padrão (DP) e do coeficiente de variação (CV) serem baixos, a distribuição dos dados foi assimétrica com coeficiente de assimetria (Cs) positivo (Quadro 2). Sangoi et al. (2012), avaliando os efeitos da variabilidade na distribuição espacial de plantas de milho na linha em dois espaçamentos entrelinhas, mantendo-se constante a densidade de semeadura, observaram em dois anos consecutivos decréscimo na produtividade dos grãos com o aumento de $10 \%$ no CV ocasionado pela redução do número de grãos produzidos por metro quadrado.

Quadro 2. Estatística descritiva para o indicador estande de plantas por metro e para os indicadores porcentagem de espaçamentos normal, falho e duplo, relacionados à distribuição longitudinal da semeadora-adubadora pneumática

\begin{tabular}{lcccc}
\hline Parâmetros & $\begin{array}{c}\text { Estande } \\
\left(\text { plantas }^{-1}\right)\end{array}$ & $\begin{array}{c}\text { Normal } \\
(\%)\end{array}$ & $\begin{array}{c}\text { Falho } \\
(\%)\end{array}$ & $\begin{array}{c}\text { Duplo } \\
(\%)\end{array}$ \\
\hline Média & 4,51 & 84,42 & 11,41 & 4,16 \\
Mediana & 4,50 & 88,20 & 11,11 & 0,00 \\
Amplitude & 2,00 & 50,00 & 37,50 & 22,22 \\
DP & 0,45 & 12,10 & 9,74 & 6,59 \\
Variância & 0,20 & 145,29 & 94,78 & 43,41 \\
CV (\%) & 9,90 & 14,28 & 85,23 & 158,38 \\
Mínimo & 3,50 & 50,00 & 0,00 & 0,00 \\
Máximo & 5,50 & 100,00 & 37,50 & 22,22 \\
Cs & 0,26 & $-0,82$ & 0,54 & 1,27 \\
Ck & 0,37 & 0,46 & 0,31 & 0,36 \\
RJ & $0,999^{\mathrm{N}}$ & $0,975^{\mathrm{N}}$ & $0,984^{\mathrm{N}}$ & $0,995^{\mathrm{N}}$ \\
\hline
\end{tabular}

CV: Coeficiente de Variação; DP: Desvio padrão; Cs: Coeficiente de assimetria, Ck: Coeficiente de curtose; RJ: Teste de normalidade de Ryan-Joiner (N: Distribuição normal; A: Distribuição assimétrica). 
Observou-se que, ao contrário do espaçamento duplo e normal, o falho apresentou média e mediana relativamente próximas, porém, com elevados índices de DP e CV. Também observaramse os maiores índices de DP, CV, média e mediana distantes para o indicador espaçamento duplo (Quadro 2). A porcentagem de espaçamentos falhos apresentou CV semelhante ao obtido por Santos et al. (2011) que, mesmo avaliando a distribuição longitudinal da semeadora-adubadora pneumática em velocidades inferiores, verificaram altos valores de $\mathrm{CV}$.

Os testes de Ryan-Joiner indicaram distribuição normal para os indicadores estande de plantas e espaçamentos normal, falho e duplo. Apesar da elevada variabilidade nos dados de espaçamentos falhos e duplos, todos os indicadores de distribuição longitudinal apresentaram valores de Cs e Ck (coeficiente de curtose) dentro do intervalo de -2 e 2, que indica que os dados respeitam uma distribuição normal (ALBIEIRO et al., 2012; MELO et al., 2013; SILVA et al., 2013).

O valor obtido para distribuição normal $(84,42 \%)$ foi abaixo da capacidade da semeadora pneumática, que deve ter como meta $90 \%$ de espaçamentos normais (TOURINO et al., 2009; MELO et al., 2013; WEIRICH NETO et al., 2015). A distribuição falha também não atingiu a meta para a distribuição longitudinal de sementes de 10\%, apesar de obter valor pouco superior. A distribuição dupla, por sua vez, apresentou-se dentro da meta de $10 \%$. Desta forma, segundo critério relatado por Tourino et al. (2009) a semeadora teve bom desempenho, considerando-se que distribuiu as sementes na faixa de 75 a $90 \%$ de espaçamentos normais.

Os resultados concordam com Carpes (2014) que avaliaram a distribuição longitudinal de sementes de milho por semeadoras de precisão em função do tubo condutor, mecanismo dosador e densidade de semeadura. Verificaram $82,86 \%$ de espaçamentos normais para dosador pneumático, e $83 \%$ de espaçamentos normais para densidades de semeadura entre 60.000 e 70.000 plantas ha1. Já Dias et al. (2014), avaliando a distribuição longitudinal em quatro mecanismos dosadores em quatro velocidades periféricas, encontraram para os mecanismos dosadores pneumáticos de pressão negativa valores próximos a $80 \%$ de espaçamentos normais.

Nas cartas de controle apresentadas na Figura 1, observou-se que, exceto para espaçamento normal, os índices dos demais indicadores de qualidade de semeadura avaliados se mantiveram sob controle estatístico, ou seja, em nenhum ponto estes ultrapassaram os UCL e LCL, portanto, havendo somente presença de causas aleatórias (intrínsecas) ao processo (VOLTARELLI et al., 2015).

Em relação à carta de controle para o indicador espaçamento normal, observou-se um ponto fora dos limites de controle, caracterizando instabilidade do comportamento da distribuição longitudinal e ocorrência de causas extrínsecas ao processo. Neste caso, as principais causas de o processo ser considerado instável podem ser atribuídas em relação aos fatores máquina, mão de obra e ambiente, em que tal instabilidade pode ser explicada em decorrência do elevado conteúdo de água no solo no momento da semeadura, impurezas no lote de sementes, e pelo fato de que o operador da máquina possa ter, eventualmente, em função de tais condições, perdido o controle do conjunto mecanizado ou alterado a velocidade bruscamente, afetando a qualidade da operação.

A instabilidade observada para espaçamento normal ocorreu na observação 57, que atingiu o limite inferior de controle. Verificou-se, no entanto, que no mesmo ponto obteve-se espaçamento falho próximo ao limite superior de controle, o que evidencia relação inversa entre estes indicadores.

Weirich Neto et al. (2015), estudando a distribuição de sementes de milho em 30 propriedades rurais por 05 anos consecutivos, destacaram como principais motivos para o aumento dos espaçamentos falhos: disco e/ou anel inadequados para a peneira do híbrido, pressão imprópria no sistema pneumático, falta ou excesso de grafite, tratamento de sementes com elevada abrasividade, posicionamento das sementes dentro do sulco, ataque de pragas, umidade do solo, contato solo-semente dificultado pela quantidade de palha no sistema de semeadura direta, umidade do solo inadequada para semeadura, abertura e fechamento do sulco.

Apesar de sujeita a fontes de variação de difícil controle, na operação de semeadura do milho 


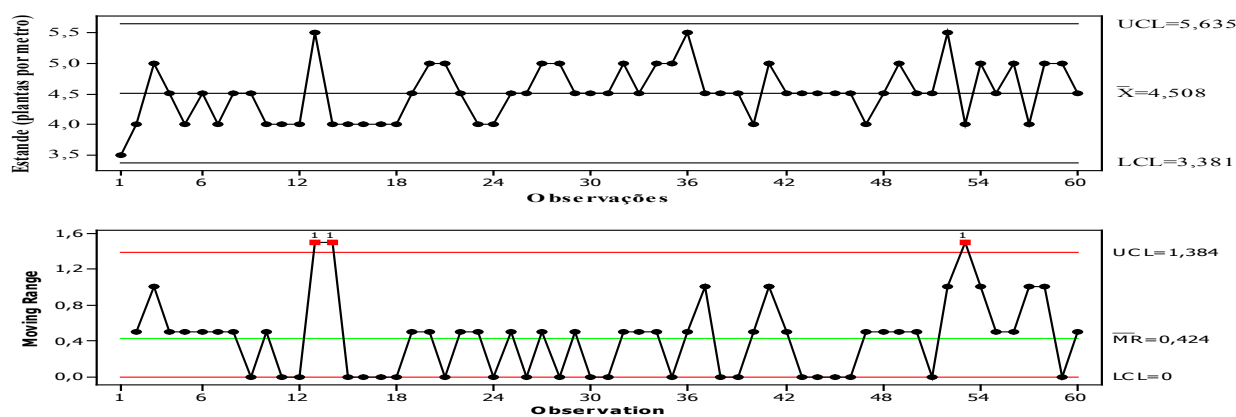

(a)
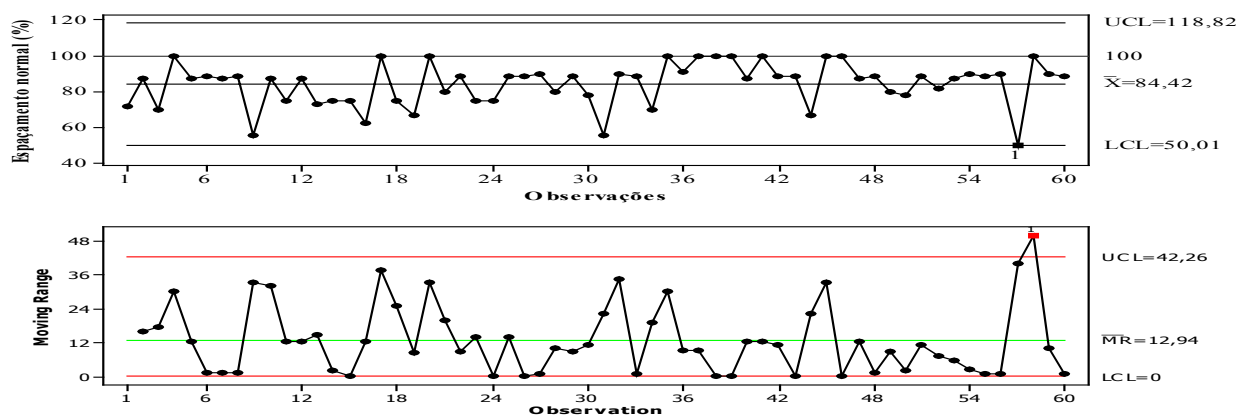

(b)
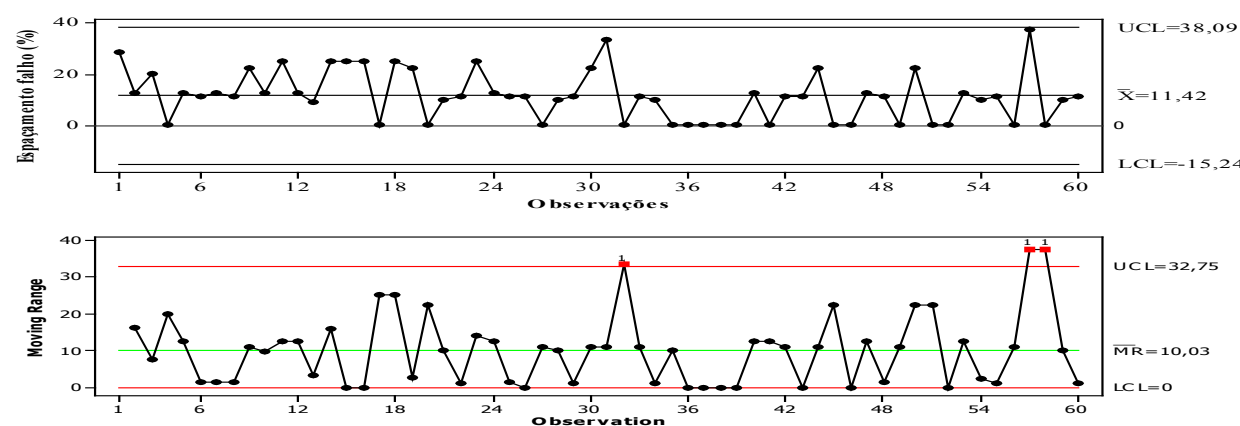

(c)

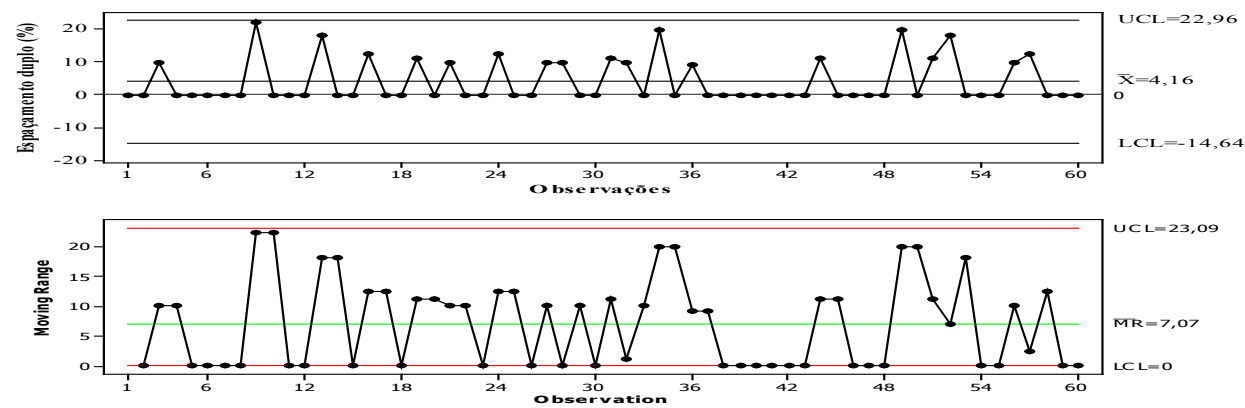

(d)

Figura 1. Cartas de controle para (a) estande de plantas por metro e (b) distribuição longitudinal em

espaçamentos normal, (c) falho e (d) duplo.
UCL: Limite superior de controle; LCL: Limite inferior de controle; ${ }{ }_{\text {: }}$ Média geral. 


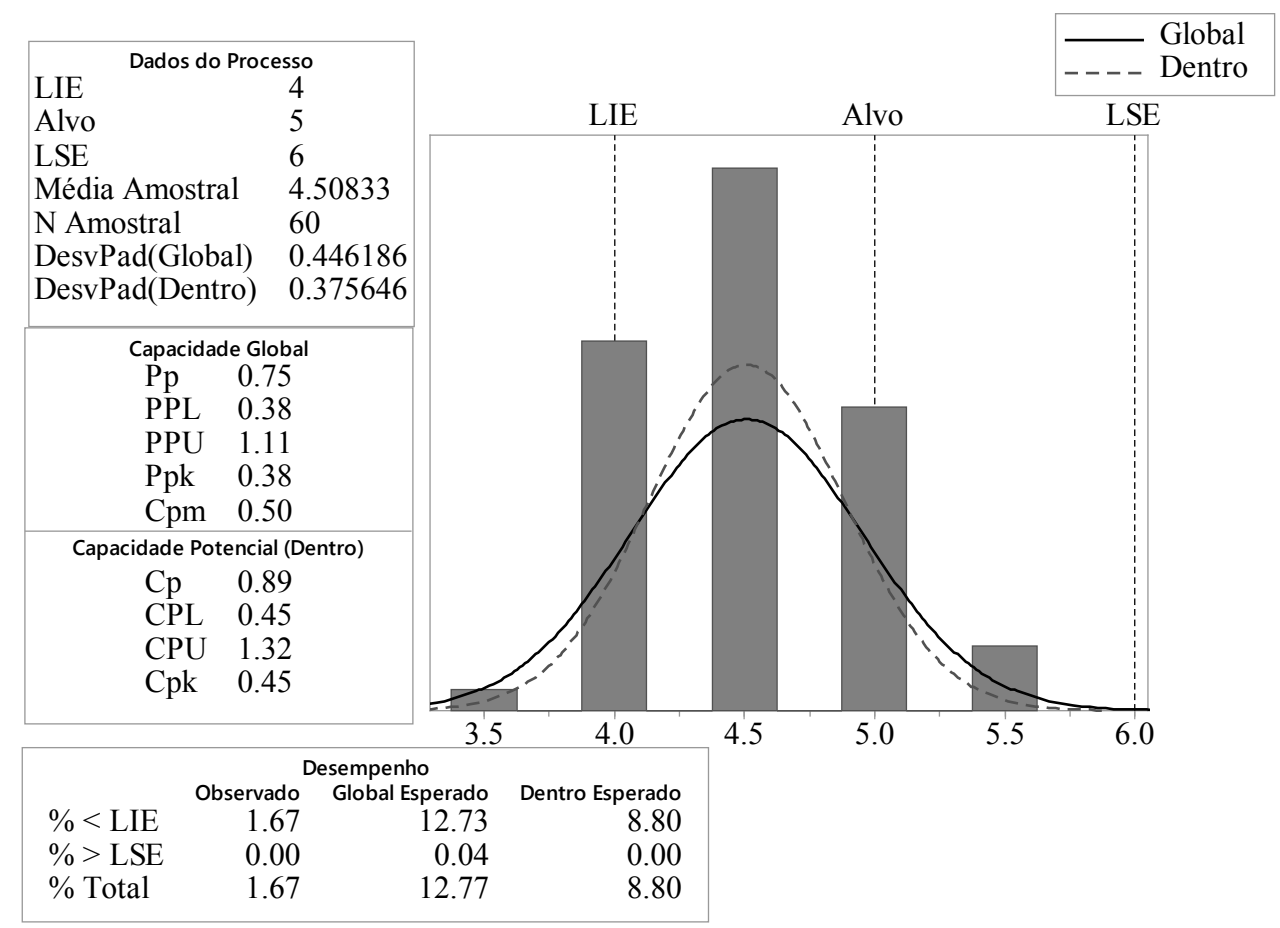

Figura 2. Análise de capabilidade do processo para estande de plantas (plantas $\mathrm{m}^{-1}$ ) de uma semeadora pneumática. LIE: limite inferior especificado; LSE: limite superior especificado.

DesvPad (Global) - desvio padrão global; DesvPad (Dentro) - desvio padrão dentro (por subgrupo).

quando implementado um plano de melhorias que contemple ações de treinamento, monitoramento e acompanhamento da equipe técnica envolvida, torna-se possível obter variação de plantas emergidas entre fileiras, espaçamentos falhos e duplos abaixo de $5 \%$, e, consequentemente, alcançar a meta acima de $90 \%$ de espaçamentos normais para semeadura da cultura do milho (WEIRICH NETO et al., 2015).

Após satisfeitas as condições de normalidade pelo teste de Ryan-Joiner para todos os indicadores, e considerados sob controle estatístico do processo estande de plantas e espaçamentos falhos e duplos, realizou-se a análise de capabilidade do processo para estes indicadores.

Os dados de estande de plantas apresentaram valor do índice $\mathrm{Cp}$ igual a 0,89 (Figura 2), que indica a capacidade baixa do processo, pois quando $\mathrm{Cp}<1,0$ o processo encontra-se como incapaz de gerar resultados satisfatórios e precisa ser revisto, desse modo, o processo de semeadura precisa ser reavaliado, por meio da inspeção e adequada regulagem para uma nova operação.
Os índices de desempenho se relacionam mais com a qualidade do processo produtivo e devido aos baixos valores, o processo foi considerado de baixa qualidade. Assim, o valor de 0,75 para o índice Pp é um indicativo de que o processo não foi capaz de produzir resultados satisfatórios em relação ao indicador estande de plantas. Para verificação do desempenho geral do processo, verificou-se que $1,67 \%$ da distribuição está fora dos limites especificados, levando-se em conta causas aleatórias e não aleatórias de variação (Figura 2).

Quanto ao desempenho geral do processo para porcentagem de espaçamentos falhos e duplos, observou-se $23,33 \%$ e $1,67 \%$, respectivamente, da distribuição dos valores observados fora dos limites especificados (Figuras 3 e 4). Mesmo na análise por subgrupo (dentro) e global, os resultados são piores, pois indicam valores fora dos limites de especificação. Além disso, os baixos valores do índice Pp demonstram resultados insatisfatórios para ambos os indicadores, conforme as especificações desejadas. 


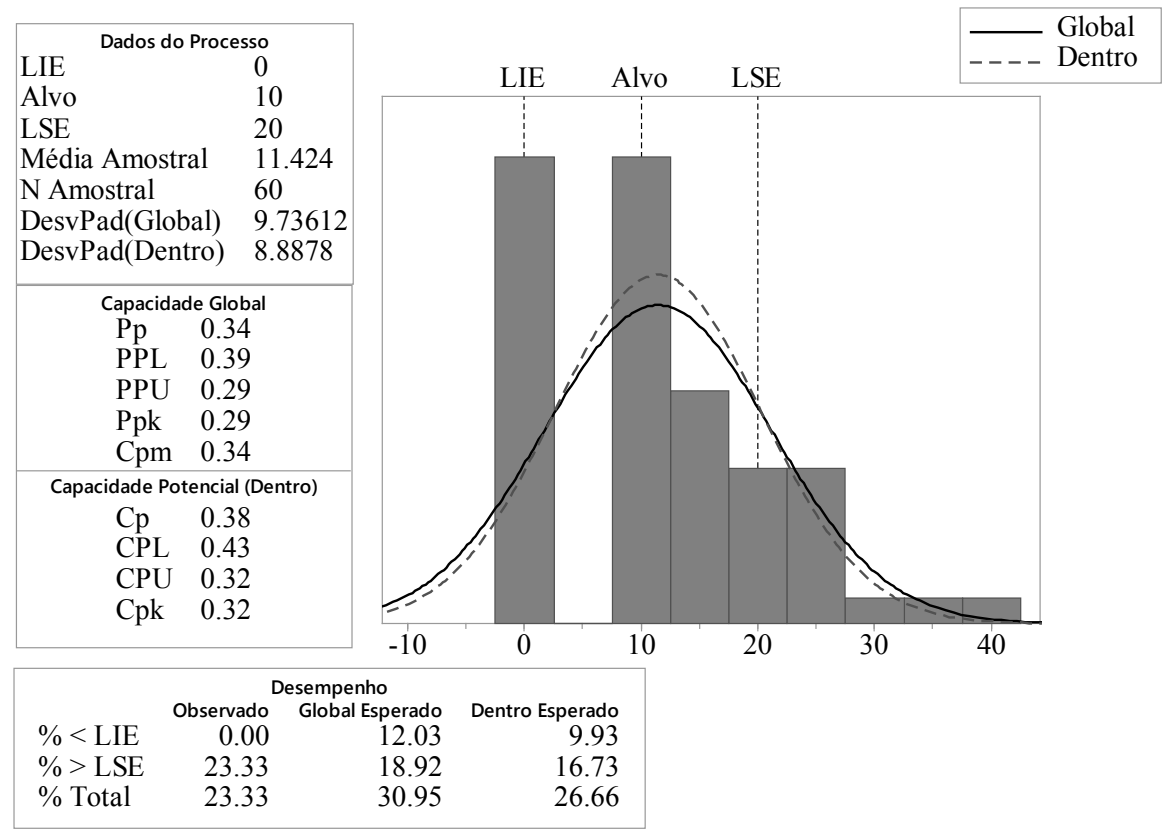

Figura 3. Análise de capabilidade do processo para distribuição longitudinal de plantas em espaçamentos falhos (\%) de uma semeadora pneumática. LIE: limite inferior especificado; LSE: limite superior especificado.

DesvPad (Global) - desvio padrão global; DesvPad (Dentro) - desvio padrão dentro (por subgrupo).

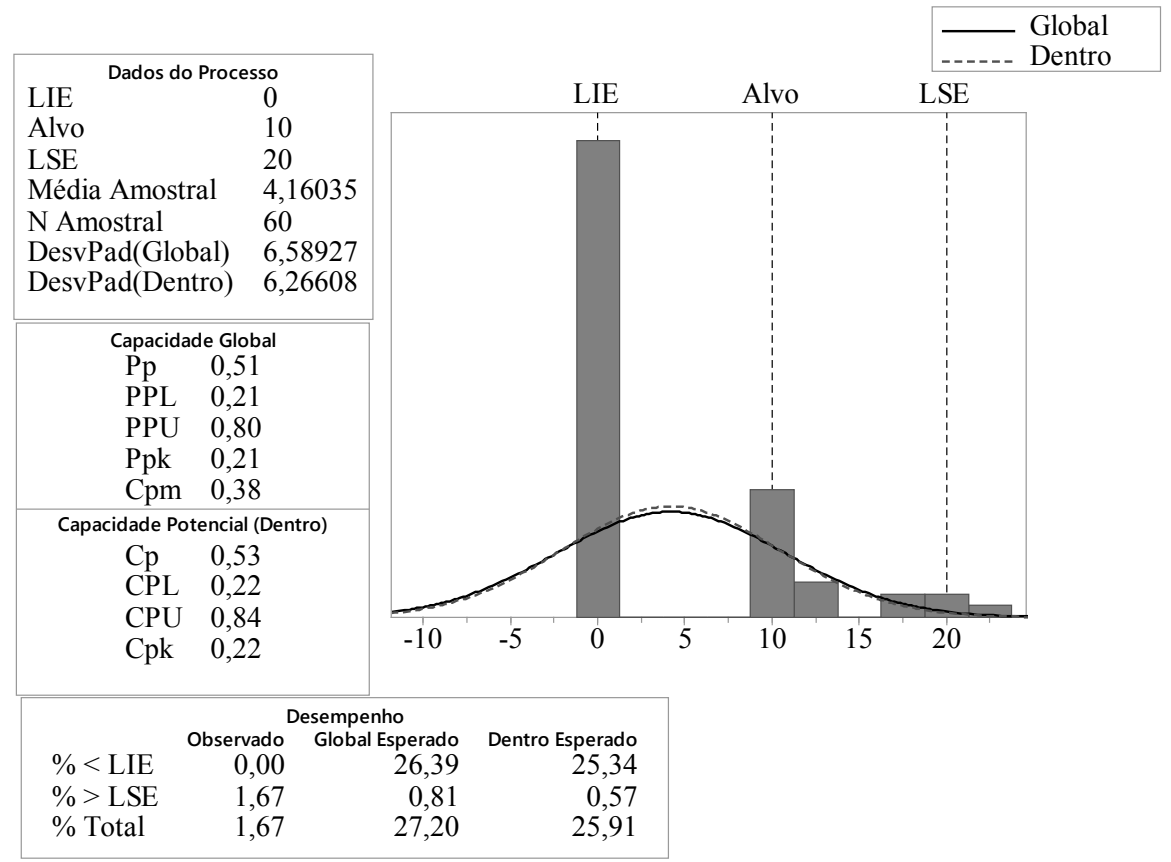

Figura 4. Análise de capabilidade do processo para distribuição longitudinal de plantas em espaçamentos duplos (\%) de uma semeadora pneumática. LIE: limite inferior especificado; LSE: limite superior especificado.

DesvPad (Global) - desvio padrão global; DesvPad (Dentro) - desvio padrão dentro (por subgrupo). 
Deste modo, a instabilidade verificada por meio do CEP para o indicador distribuição longitudinal em espaçamentos normais, quanto à incapacidade da semeadora-adubadora pneumática em produzir resultados satisfatórios baseados na meta (alvo) para os indicadores estande de plantas, espaçamentos falhos e duplos a partir da análise de capabilidade, evidenciam a necessidade de estabelecer na propriedade rural um plano de melhorias que contemple ações de treinamento, monitoramento e acompanhamento da equipe técnica envolvida na operação de semeadura do milho de segunda safra.

\section{CONCLUSÕES}

- O indicador estande de plantas por metro foi considerado satisfatório, estando pouco abaixo da população recomendada;

- Os indicadores espaçamentos falhos e duplos apresentaram elevada variabilidade, o que reduziu a distribuição longitudinal de plantas em espaçamentos normais, abaixo da meta de $90 \%$ esperada para semeadoras-adubadoras dotadas de dosador pneumático;

- O controle estatístico do processo permitiu avaliar a qualidade dos indicadores durante o processo de semeadura, demostrando instabilidade para o indicador porcentagem de espaçamentos normais e estabilidade dos índices de porcentagens de espaçamentos falhos e duplos, e do estande de plantas;

- Os resultados da análise de capabilidade do processo indicaram que a semeadora pneumática não atingiu as metas estabelecidas para estande de plantas e espaçamentos falhos e duplos, sugerindo que há necessidade de maior monitoramento da operação.

\section{AGRADECIMENTOS}

À Capes, pela bolsa de estudo concedida ao primeiro autor. Ao CNPq, pelas bolsas de pesquisa e de iniciação científica concedidas.

\section{REFERÊNCIAS BIBLIOGRÁFICAS}

ALBIERO, D.; MACIEL, A.J.S.; MILAN, M.; MONTEIRO, L.A.; MION, R.L. Avaliação da distribuição de sementes por uma semeadora de anel interno rotativo utilizando média móvel exponencial. Revista Ciência Agronômica, v.43, n. 1, p.86-95, 2012.

CARPES, D.P. Distribuição longitudinal de sementes de milho e soja em função do tubo condutor, mecanismo dosador e densidade de semeadura. 2014. 90f. Dissertação (mestrado em Engenharia Agrícola) - Universidade Federal de Santa Maria, Santa Maria, 2014.

CASSIA, M.T.; SILVA, R.P.; CHIODEROLLI, C.A.; NORONHA, R.H.F.; SANTOS, E.P. Quality of mechanized coffee harvesting in circular planting system. Ciência Rural, v.43, n.1, p.28-34, 2013.

DIAS, V.O.; ALONÇO, A.S.; CARPES, D.P.; VEIT, A.A.; SOUZA, L.B. Velocidade periférica do disco em mecanismos dosadores de sementes de milho e soja. Ciência Rural, v.44, n.11, p.19731979, 2014.

EMBRAPA - Empresa Brasileira de Pesquisa Agropecuária. Centro Nacional de Pesquisa de Solos. Sistema Brasileiro de Classificação de Solos. Rio de Janeiro. 2006. 306p.

KURACHI, S.A.H.; COSTA, J.A.S.; BERNARDI, J.A.; COELHO, J.L.D.; SILVEIRA, G.M. Avaliação tecnológica de semeadoras e/ou adubadoras: tratamento e dados de ensaios e regularidade de distribuição longitudinal de sementes. Bragantia, v.48, n.2, p.249-262, 1989.

MELO, R.P.; ALBIERO, D.; MONTEIRO, L.A.; SOUZA, F.H.; SILVA, J.G. Qualidade na distribuição de sementes de milho em semeadoras em um solo cearense. Revista Ciência Agronômica, v.44, n.1, p.94-101, 2013.

NORONHA, R.H.F.; SILVA, R.P.; CHIODEROLI, C.A.; SANTOS, E.P.; CASSIA, M.T. Controle estatístico aplicado ao processo de colheita mecanizada diurna e noturna de cana-de-açúcar. Bragantia, v.70, n.4, p.931-938, 2011.

PELOIA, P.R.; MILAN, M.; ROMANELLI, T.L. Capacity of the mechanical harvesting process of 
sugar cane billets. Scientia Agricola, v.67, n.6, 2010.

SANGOI, L.; SCHMITT, A.; VIEIRA, J.; PICOLI, G.J.; SOUZA, C.A.; CASA, R.T.; SCHENATTO, D.E.; GIORDANI, W.; BONIATTI, C.M.; MACHADO, G.C.; HORN, D. Variabilidade na distribuição espacial de plantas na linha e rendimento de grãos de milho. Revista Brasileira de Milho e Sorgo, v.11, n.3, p.268-277, 2012.

SANTOS, A.J.M; GAMERO, C.A.; OLIVEIRA, R.B.; VILLEN, A.C. Análise espacial da distribuição longitudinal de sementes de milho em uma semeadora-adubadora de precisão. Bioscience Journal, v.27, n.1, p.16-23, 2011.

SILVA, M.R.; MARTIN, T.N.; ORTIZ, S.; BERTONCELLI, P.; VONZ, D. Desempenho agronômico de genótipos de milho sob condições de restrição hídrica. Revista de Ciências Agrárias, v.35, n.1, p.202-212, 2012.

SILVA, R.P.; CASSIA, M.T.; VOLTARELLI, M.A.; COMPAGNON, A.M.; FURLANI, C. E.A.F. Qualidade da colheita mecanizada de feijão em dois sistemas de preparo do solo. Revista Ciência Agronômica, v.44, n.1, p.61-69, 2013.

TOLEDO, A. Variabilidade espacial e diagnóstico da qualidade do processo em semeadura de amendoim. 2008. 96f. Dissertação (Mestrado em Agronomia) - Universidade Estadual Paulista Júlio de Mesquita Filho, Jaboticabal, 2008.

TOURINO, M.C.C.; REZENDE, P.M.; SILVA,
L.A.; ALMEIDA, L.G.P. Semeadoras-adubadoras em semeadura convencional de soja. Ciência Rural, v.39, n.1, p.241-245, 2009.

VIAN, A.L.; SANTI, A.L.; AMADO, T.J.C.; CHERUBIN, M.R.; SIMON, D.H.; DAMIAN, J.M.; BREDEMEIER, C. Variabilidade espacial da produtividade de milho irrigado e sua correlação com variáveis explicativas de planta. Ciência Rural, v.46, n.3, p 464-471, 2016.

VOLTARELLI, M.A. Qualidade da operação de plantio mecanizado de cana-de-açúcar nos turnos diurno e noturno. 2013. Ano de obtenção: 2013. 168p. Dissertação (Mestrado em Agronomia) - Universidade Estadual Paulista Júlio de Mesquita Filho, Jaboticabal, 2013.

VOLTARELLI, M.A.; SILVA, R.P.; CASSIA, M.A; ORTIZ, D.F.; TORRES, L.S. Quality of performance of the operation of sugarcane mechanized planting in day and night shifts. Engenharia Agrícola, v.35, n.3, p.528-541, 2015.

VOLTARELLI, M.A.; SILVA, R.P.; ROSALEN, D.L.; ZERBATO, C.; CASSIA, M.A. Quality of performance of the operation of sugarcane mechanized planting in day and night shifts. Australian Journal Crop Science, v.7, n.9, p.1396-1406, 2013.

WEIRICH NETO, P.H.; FORNARI, A.J.; JUSTINO, A.; GARCIA, L.C. Qualidade na semeadura do milho. Engenharia Agrícola, v.35, n.1, p.171-179, 2015. 